\title{
Assessment of herbs and spices extracts/meal on rumen fermentation: Review
}

\author{
${ }^{1}$ Tolulope Oreoluwa Faniyi', Ênio Rosa Prates ${ }^{2 *}$, Micheal Kolawole Adewumi', Temitope \\ Bankole ${ }^{1}$ \\ ${ }^{I}$ Department of Animal Science, Faculty of Agriculture and Forestry, University of Ibadan, Ibadan, Nigeria: \\ tolfan2003@yahoo.com \\ ${ }^{2}$ Departamento de Zootecnia, Faculdade de Agronomia, Universidade do Rio Grande do Sul, Porto Alegre, Brazil. \\ *Autor para correspondência, E-mail:00001450@ufrgs.br
}

\begin{abstract}
The ban on antibiotics use in animal agriculture especially in Europe and the increased awareness of the consumers about the health hazards that occurs due to the use of antibiotics as feed additives in animal nutrition triggered a need for natural and safe feed additives such as plant extracts. Therefore, there is a need to explore/exploit different natural plant products to achieve better production in farm animals. Herbs and spices are known to have health benefits on animals when used as feed additives in animal nutrition. For effective use of herbs and spices, they can be added to feed as dried plants or as extracts. Ruminants have been adapted to fill an important ecological niche because of their specially adapted digestive tract that allows them to survive on fibrous feeds. However, the degradation of these feeds in the rumen leads to loss in terms of methane production and nitrogenous wastage. Methane loss represents about $12 \%$ of the gross energy of feed fed to the animals. Because of these reasons, there is need to manipulate the rumen microbial ecosystem for the purpose of improving ruminants production efficiency. Recently, many researchers have diverted their attentions to the use of extracts/meal from herbs and spices because of their great potentials. Many researches has been carried out by various researchers using different extracts/meal of some herbs and spices using in vitro gas production techniques to manipulate rumen microbial ecosystem in order to improve the productivity of ruminants. From the findings of these researches, it can be concluded that extracts of herbs and spices have a great potential in manipulating the process of rumen fermentation thereby reducing methane production, decreasing ammonium concentration and other rumen fermentation parameters.
\end{abstract}

Keywords: Herbs and spices, gas production techniques, methane loss, nitrogenous wastage

\section{Introduction}

The ban on nutritive antibiotics use by the European Union (OJEU, 2003) in animal agriculture and the increased awareness of the consumers about the health hazards that occurs due to the use of antibiotics as feed additives in animal nutrition triggered a need for natural and safe feed additives such as organic acids, probiotics, prebiotics and plant extracts as a substitute to the use of antibiotics and other chemical sources in animal nutrition (Jayasena \& Jo, 2013). The residual effect of the antibiotics and other chemical sources found in meat and milk products can give rise to transmissible resistance factors that may lead to health problems and compromise the therapeutic use of antibiotic in humans (Casewell et al., 2003, Russell \& Houlihan, 2003). Therefore, there is a need to exploit different natural plant products to achieve better production of farm

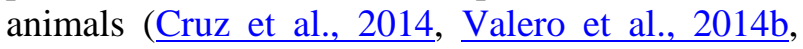
Valero et al., 2015).

For some years past, the use of natural feed additives in animal nutrition has been encouraged. A large number of plant species contains various chemical substances which possess health benefits such as anti-microbial action, anti-inflammatory 
action, anti-oxidative action, immunostimulant function and appetite/digestion stimulants. (Patra, 2011, Bodas et al., 2012, Patra \& Saxena, 2010, Benchaar et al., 2008a). Thousands of years ago, plants and their extracts were already used in Mesopotamia, Egypt, India, China and old Greece, where they were valued because of their specific aroma and various medicinal properties (Greathead, 2003). The composition of extracts from a plant depends on the extraction method and the properties of the extraction solvent used. Plants contain some secondary metabolites, which are responsible for certain biological and physiological effects (Calsamiglia et al., 2007). The amount of these secondary metabolites varies depending on the variety of plant, age, growing conditions etc.(Benchaar et al., 2008a).

Herbs and spices (such as cinnamon, oregano, thyme, ginger, garlic etc) are known to have health benefits (such as appetite and digestion stimulants (Janz et al., 2007, Srinivasan, 2005), anti-microbial action (Pasqua et al., 2006, Windisch et al., 2008), anti-inflammatory action (Craig, 1999, Srinivasan, 2005), anti-oxidative action (Craig, 1999, Fasseas et al., 2008) and immunostimulant function (Craig, 1999) on animals when used as feed additives in animal nutrition. For effective use of herbs and spices, they can be added to feed as dried plants or as extracts. Ruminants have been adapted to fill an important ecological niche because of their specially adapted digestive tract that allows them to survive on fibrous feeds. Ruminants are able to utilize much of plant materials that cannot be utilized to any appreciable extent by simple stomach animals because of a large part of the carbohydrate that contains simple sugars joined together by $\beta$-links such as cellulose (Van Soest, 1994). In the developing countries, fibrous feeds such as crop residues, agro-industrial by-products and natural pasture or native grass, which are of low digestibility takes a larger percentage of feeds available to most ruminants under small scale production system (Wanapat et al., 2009, Moreira \& Prado, 2010). A major characteristic of these fibrous feeds is their slow rate of degradation in the rumen by microbes, which result into much nutrients present in the feed voided in faeces (Teferedegne, 2000, Wanapat, 2000). On the other hand, high levels of energy and protein are required in feeding ruminant in intensive production systems, especially for dairy production. Thus, animals are fed on rations rich in starch and high quality protein, which are fermented very rapidly. There are microorganisms (bacteria, fungi, protozoa and methanogens) which are responsible for the breaking down of this plant materials in a process called rumen fermentation. A symbiotic relationship is established between ruminants and rumen microorganisms in which the animal provides nutrients and optimal environmental conditions for the fermentation of feeds by the microorganisms. The microorganisms degrade carbohydrate and protein present in the feed thereby synthesizing microbial protein in order to supply energy and protein to the animal. It is well know that the rapid degradation of carbohydrates leads to the production of volatile fatty acids (VFA's). In the synthesis of this VFA's, hydrogen is produced in which much of it undergoes a chemical reaction in methanogenic bacteria (such as Methanobacterium formicicum, $M$. ruminantium, $M$. bryanti, Methanobrevibacter ruminantium, Methanosarcina barkeri, Methanomicrobium mobile and Methanoculleus olentangyi) thereby leading to methane production. The methane produced must be expelled together with $\mathrm{CO}_{2}$ through the process of eructation (Bunglavan, 2014). Methane loss is a major problem that is always associated with green house effect and it also represent economic loss to farmers in that energy loss in the form of methane should rather be used in the process of meat and milk production in ruminant livestock (Åby et al., 2013). Methane loss represents about $12 \%$ of the gross energy of feed fed to the animals (Patra, 2012). About $95 \%$ of the global animal enteric methane is from ruminants, which is a consequence of their large population, body size and feed intake (Donald \& Ward, 1996). The rapid breakdown of dietary protein to ammonia increases nitrogenous wastage rather than contributing directly to the animal's nutrient requirements in order to increase productivity. About 75 to $85 \%$ of nitrogen consumed by dairy cows is excreted in the faeces and urine (Tamminga, 1992, Gunjan \& Makkar, 2012, Patra, 2012) and it also has negative impact on the environment by increasing nitrous oxide emissions in the atmosphere (Boadi et al., 2004).

Because of these reasons, there is need to manipulate the rumen microbial ecosystem for the 
purpose of improving ruminants production efficiency. Rumen microbial population can be manipulated by adding extracts/meal of herbs and spices as feed additives to eliminate or reduce rumen ciliate protozoa (defaunation), reduce protein degradation and methane production.

Recently, many researchers have diverted their attentions to the use of extracts/meal from herbs and spices because of their great potentials as alternatives to antibiotics for the purpose of manipulating rumen ecosystem in ruminant nutrition and growth. Many researches has been carried out by various researchers using different extracts/meal of some herbs and spices in association with various techniques to manipulate rumen microbial ecosystem in order to improve the productivity of ruminants (Geraci et al., 2012, Patra
\& Saxena, 2010, Benchaar et al., 2008a, Calsamiglia et al., 2007, Jayasena \& Jo, 2013). The purpose of this review is to investigate the effect of extract/meal of some herbs and spices on rumen fermentation using in-vitro gas technique.

\section{Herbs and spices}

The use of plant extracts appears as one of the most natural alternatives to antibiotic use in animal nutrition (Bunglavan, 2014). The natural occurrence of plants and their extracts makes them safe for consumption (FDA, 2004). Plant extracts has been used in the past decades for various purposes such as medicinal purpose, food preservatives etc. because of their antimicrobial properties (Davidson \& Naidu, 2000).

Table 1: Some plants, their often used parts and major active components

\begin{tabular}{lcc}
\hline Plants & Used part & Major active component \\
\hline Ginger & Rhizome & Zingerone \\
Cinnamon & Stem bark & Cinnamldehyde, eugenol \\
Horse radish & Root & Allylisothiocyanate \\
Mint & Leaf & Menthol, 1,8-cineole \\
Oregano & Leaf & Carvacrol, thymol \\
Rosemary & Leaf & 1,8 -cineol \\
Clove & Flower bud & Eugenol, eugenol acetate \\
Garlic & Bulb & Allicin, diallyl disulphide \\
Methyl- $n$-propyl disulphide & Onion & Bulb \\
Cumin & Seed & Cuminaldehyde \\
White mustard & Seed & Allylisothiocyanate \\
Nutmeg & Kernel/Fruit seed & Sabinene \\
Pepper & Fruit/Fruit pulp & Piperine, monoterpenes \\
Star anise & Fruit/Fruit pulp & Anethol \\
Cardamom & Fruit/Fruit pulp & Cineol \\
Thyme & Whole plant & Thymol \\
\hline
\end{tabular}

Source: Afshar (2012).

Before the advent of antibiotics, herbs have been used all over the world by all cultures for centuries in which each part of the world uses herbs that are local to the area. Western herbs tend to work slowly to restore health and balance to the body, while Chinese herbology contains some fast acting herbs (Afshar, 2012). Herbs are flowering, non-woody and non-persistent plants while spices are herbs with an intensive smell and taste commonly added to human foods (Odoemelam et al., 2013, Achinewhu et al., 1995, Vadivel et al., 2011, Marcus, 2013). They fall into the class of feed additives known as phytogenic and they contain some chemical substances that are known to trigger definite physiological responses in the body of animals (Windisch et al., 2008). Plants 
readily synthesize some chemical substances for their defense against insects, diseases, herbivores and harsh environmental conditions and they may also produce secondary antimicrobial metabolites as part of their normal growth and development (Afshar, 2012). The most important bioactive compounds present in herbs and spices include alkaloids, glycosides, flavonoids, phenolic acids, saponins, tannins, terpenes, anthraquinones, essential oils and steroids (Brenes \& Roura, 2010, Patra \& Saxena, 2010, Groussin \& Antoniotti, 2012). The use of herbs and spices is increasingly gaining relevance in livestock production. Parts of herbs and spices that are make used for various purposes include rhizome (ginger, turmeric), stem bark (cinnamon), tubers (galangal), root (horseradish), leaf (mint, oregano, basil), flower bud (clove), bulb (garlic, onion), seed (sesame, cumin, white mustard), kernel/fruit seed (nutmeg), and fruit/ fruit pulp (pepper, black pepper, star anise, cardamom) (Calsamiglia et al., 2007).

Some of the research findings revealed that the use of herbs and spices as feed additives in animal nutrition improved feed conversion ratio, body weight, feed intake, palatability and acceptability of feed by the animals (Cruz et al., 2014, Valero et al., 2014a, Valero et al., 2014b, Zawadzki et al., 2011). Zigger (2001) using garlic and cinnamon extracts reported increase in feed intake and live weight gain of weaned pigs fed feed supplemented with garlic and cinnamon extracts. Lippens et al. (2005) observed a significantly higher body weight in chicken supplemented with plant extract in an experiment conducted to determine the effect of a mixture of cinnamon, oregano, thyme, cayenne pepper and citrus extracts and a mixture of plant extracts and organic acids in comparison to nutritive antibiotic avilamicin in broiler chickens. The higher body weight observed was a consequence of increased feed consumption.

\section{The use of herbs and spices in ruminant nutrition}

In recent years, the use of herbs and spices has been of great interest in ruminant nutrition (Chaves et al., 2012, Chaves et al., 2011, Chaves et al., 2009, Chaves et al., 2008b). The rumen ecosystem is composed of complex anaerobic microbial population of bacteria, fungi, protozoa and methanogens (Van Soest, 1994). The ban on antibiotics by the European Union (OJEU, 2003) led to increase in production cost and this has prompted researchers in search for possible alternatives that will be effective in the manipulation of microbial fermentation in the rumen of ruminant livestock. What the researchers aim to achieve by manipulating the rumen fermentation process using herbs and spices include increase in the effectiveness of digestion and metabolism of nutrients, suppression of energy loss through the undesirable process of methanogenesis and overall increase in the productivity of the animals. In the past decades, antibiotics and other feed additives were used to increase the productivity of the animals in terms of meat, milk and wool production in intensive farming systems (Goodrich et al., 1984, Ipharraguerre \& Clark, 2003). The effect of active components from herbs and spices depends largely on the dosage used. No effect whatever can be observed at small dosage whereas large amount of dosage can even be toxic to the animals (Frankic et al., 2009).

Numerous research that has been carried out on the effectiveness of herbs and spices as feed additives shows the beneficial effects of herbs and spices on nutrition, rumen fermentation and productivity of sheep, goats, calves, heifers, dairy cows and beef cattle, feed intake, immune functions and health Cardozo (Busquet et al., 2005a, Cardozo et al., 2006, Cardozo et al., 2005, Cardozo et al., 2004, Chaves et al., 2008a, Chaves et al., 2009, Chaves et al., 2008b, Chaves et al., 2008c, Greathead, 2003, Kraszewski et al., 2002). Researchers found out that improvement in the digestibility of different nutrients is probably due to the increase in gross activity of rumen microorganisms, increased total volatile fatty acids (TVFAs) concentration, increase in dry matter intake and weight gain rate by the animals (Ahmed et al., 2009). Esparza-Borges \& Ortiz-Márquez (1995) evaluated the therapeutic effect of extracts of garlic (Allium sativum, L), eucalyptus (Eucalyptus globulus, Labill.) and gordolobo (Gnaphalium conoideum) on acute endometritis of Holstein cows. The result indicated that garlic was the most effective of all the extracts; however, eucalyptus was also effective but more treatments were needed.

The antioxidant effect of marigold, grape, 
rosemary and citrus extracts was tested on sheep by Gladine et al. (2007a), Gladine et al. (2007b) using linseed oil to induce lipid peroxidation by its continuous infusion into the duodenum. The extracts were applied directly into rumen through the rumen cannula. The results showed that all tested plant extracts maintained their antioxidant capability in vivo in sheep. However, it was observed that marigold extract was the most bioefficient in preventing the occurrence of lipid peroxidation.

Chaves et al. (2008b) in a study carried out to examine the effects of cinnamaldehyde, garlic and juniper berry essential oils on performance and carcass characteristics of lambs fed a barley-based concentrate diet ad libitum reported that feeding cinnamaldehyde or juniper berry supplemented diet increased average daily gain and numerically improved feed conversion efficiency. However, the addition of cinnamaldehyde, garlic or Juniper berry did not affect carcass characteristics, meat quality, and had small effects on fatty acid composition of back fat and liver. Kudke et al. (1999) supplemented calves with powder of Azadirachta indica leave and observed that calves supplemented with powder of Azadirachta indica leave had higher weight gain and less incidence of parasitic infections compared to the unsupplemented calves.

Cardozo et al. (2005) tested the effect of six natural plant extracts (garlic, cinnamon, anise, yucca, oregano and capsicum extract) and three secondary plant metabolites (cinnamaldehyde, eugenol, anethole) at five doses and two different $\mathrm{pH}$ (7.0 and 5.5) on in vitro microbial fermentation using ruminal fluid of heifers and the results showed that the effect of herbs and spices on ruminal fermentation in beef cattle may be different depending on the $\mathrm{pH}$ of the rumen. It was observed that at $\mathrm{pH} 5.5$, garlic, capsicum, yucca and cinnamaldehyde modified ruminal fermentation in favour of propionate than acetate.

There are various plant secondary metabolites such as tannins and saponins, which suppress the bacteriolytic activity of rumen ciliate protozoa thereby enhancing total microbial protein flow from the rumen. Tannins can positively affect protein digestion in ruminants by binding to proteins and forming complexes thereby reducing their solubility and degradation by rumen bacteria
(Patra \& Saxena, 2011, Hassanat \& Benchaar, 2012). These proteins, which pass through the rumen undegraded by the rumen microbes are then successfully utilized by the animal and provide the proteins necessary for the optimal productivity of the animals (Waghorn et al., 1990).

\section{Effects of extract/meal of herbs and spices in rumen fermentation}

Adopting feeding strategies that will minimize the amount of energy lost as methane and reduce ammonia concentration can improve feed conversion efficiency, improve animal productivity and reduce global warming (Gebrehiwot, 2014). Research findings reported by researchers has shown that manipulation of rumen microbial fermentation to decrease methane and ammonia production from ruminant livestock using extracts/meal of herbs and spices has proven to be a potential useful strategy in improving production efficiency in ruminants and replacing the use of antibiotics which has raised public concerns in livestock production because of the development of drug resistant bacteria (Benchaar et al., 2007, Benchaar \& Greathead, 2011, Benchaar et al., 2008b). The results obtained from the use of these herbs and spices depend mainly on their properties (biologically active compounds present in them) and ability to influence rumen environment (Szumacher-Strabel \& Cieślak, 2010, Cieslak et al., 2013).

Rezaei \& Pour (2012) reported that the addition of thyme methanolic extracts had a reducing effect on the degradability of soybean meal using in vitro gas production technique. The result showed that gas production was reduced on addition of extract of thyme. Chaudhry \& Khan (2012) in an in vitro rumen fermentation test at Newcastle University involving five curry spices which include coriander, turmeric, cumin, clove and cinnamon revealed that the spices acted as natural antibiotics, killing methane producing bacteria in the animal's gut which lead to reduction in methane production, thereby allowing less harmful bacteria to increase in number and flourish. It was discovered that coriander caused a $40 \%$ reduction in methane production.

In an in vitro study on rumen microbial fermentation, Dong et al. (2010) reported a reduction in methane production, increased 
propionate production and decreased protozoa numbers to a certain extent using luzerne extract (LE), Artemisiae annuae extract (AAE) and mixed herbal medicine (MHM) into different goat diets. Also, the inhibitory effects of the phytogenic products on methane production are more remarkable in the mixed-grass diet.

In another study carried out to assess the effect of ginger (Zingiber officinale) on the in vitro rumen ecosystem of sheep, Mohammad \& Moeini (2015) reported that ginger supplementation improved ruminal fermentation due to reduction in ammonia, reduction in methane loss, reduction in acetate to propionate ratio and beneficial changes in protozoa population. Tag El-Din et al. (2012) also conducted a research to determine the effect of ginger (zingiber officinale) and garlic (allium sativum) on gas production, energy values, organic matter digestibility and methane emission in vitro. It was concluded from this research that the addition of garlic juice and ginger improved rumen fermentation, increased gas production and reduced methane production. Busquet et al. (2005a) also reported that garlic oil altered rumen fermentation by reducing the acetate to propionate ratio in a manner similar to what is obtainable using monensin (MO) in a continuous culture. Kim et al. $\underline{(2012 b)}$ in their findings also reported that plant extracts (Artemisia princeps var. Orientalis; Wormwood, Allium sativum for. Pekinense; Garlic, Allium cepa; Onion, Zingiber officinale; Ginger, Citrus unshiu; Mandarin orange, Lonicera japonica; Honeysuckle) were shown to have properties to reduce methane production, reduce acetate to propionate ratio, decrease methanogen population and increase fibrolytic bacteria population. Fraser et al. (2007) in a study conducted on the effect of cinnamon leaf oils on rumen microbial fermentation in two continuous culture systems observed significant antimicrobial activity (through a reduction in diet digestibility and total VFA concentration) and reduced ammonia concentration in the group which received cinnamon leaf oils compared to the control group. They however observed that supplementation with cinnamon leaf oil at the dosage evaluated may have adverse effects on the metabolism and productivity of ruminants.

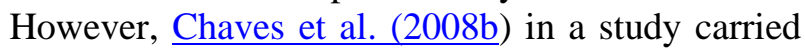
out to examine the effects of cinnamaldehyde, garlic and juniper berry essential oils on performance and carcass characteristics of lambs fed a barley-based concentrate diet ad libitum reported that supplementing the diet with cinnamaldehyde, garlic or juniper berry had no effect on any of the ruminal fermentation parameters measured. This contradicts the result findings from different in vitro studies which indicated that cinnamaldehyde and garlic alter ruminal nitrogen metabolism, increase propionate and reduce acetate and methane production in vitro (Busquet et al., 2005b, Kim et al., 2012a, Fraser et al., 2007, Calsamiglia et al., 2007).

Benchaar et al. (2007) in a study to investigate the effects of essential oils (cinnamon leaf oil, clove leaf oil, sweet orange oil, oregano oil, thyme oil) and their components (carvacrol, cinnamaldehyde, eugenol, and thymol) on in vitro rumen microbial fermentation using batch culture reported that of the essential oils and essential oil compounds evaluated, only the phenolic compounds (carvacrol, thymol, and eugenol) affected ruminal fermentation. The authors stressed that at the doses evaluated in the study, essential oils and essential oil compounds showed no beneficial effects on rumen microbial fermentation. They however recommend further research to asses in vivo, the effects of essential oils and their constituents on rumen microbial fermentation. Mariam et al. (2014) in a study to investigate the potential impacts of different levels of essential oils blend (eucalyptus, cinnamon, peppermint, thyme and lemon) on rumen fermentation parameters and nutrient utilization in barki sheep reported that there were no significant effects among investigated levels of essential oil blend on in vitro gas production and methane production, short chain fatty acids (SCFA), $\mathrm{NH}_{3}-\mathrm{N}$ concentration and protozoa count. They however suggested from the result of the study that the combination of the five essential oils had an additive effect on the chemical profiles of the blend, which may be responsible for the lack response on methane emission, rumen microbial fermentation and apparent total tract digestibility of nutrients except decreasing the digestibility of crude protein.

In another study carried out by Arhab et al. (2013) to determine the impact of essential oils extracted from Juniperus phoenicea, Satureja calamintha and Mentha pulegium on methane 
production and rumen fermentation traits of vetchoat hay in vitro, the result showed that the three essential oil tested decreased methane production and also decreased ammonia $\mathrm{N}$ concentration at all doses tested. The authors further recommend further in vitro and in vivo trials to determine the optimum dose, which reduce methane production without adversely affecting fermentation and rumen function.

\section{Conclusion}

From the findings of several researches that has been carried out on the use of Extracts/meal of herbs and spices on rumen fermentation using gas production technique, it can be concluded that extracts of herbs and spices has a great potential in manipulating the process of rumen fermentation thereby reducing methane production, decreasing ammonium concentration and other rumen fermentation parameters. However, further research should be carried out on in vivo studies to determine the optimum dosage at which these herbs and spices should be supplemented in ruminants feed to prevent toxicity problems that could occur due to high dosage of supplementation.

\section{Conflict Interest}

There was no conflict interest among the authors.

\section{Acknowledgement}

This review was written when I was under the financial support of TWAS (The world Academy of Science) and $\mathrm{CNPq}$ (Conselho Nacional de Desenvolvimento Cientifico e Tecnological Brazillian Scientific and Technological Development Council).

\section{References}

Aby, B. A., Aass, L., Sehested, E. \& Vangen, O. (2013). Effect of incorporating greenhouse gas emission costs into economic values of traits for intensive and extensive beef cattle breeds. Livestock Science, 158, 1-11.

Achinewhu, S. C., Ogbonna, C. C. \& Hart, A. D. (1995). Chemical composition of indigenous wild herbs, spices, fruits, nuts and leafy vegetables used as food. Plant Foods for Human Nutrition, 48, 341-348.
Afshar, M. A. (2012). Importance of medical herbs in animal feeding: A review. Annals of Biological Research, 3, 918-923.

Ahmed, A. A., Bassuony, N. I., El-Habiab, S. A., Awad, S., Aiad, A. M. \& Mohamed, S. A. (2009). Adding natural juice of vegetables and fruitage to ruminant diets (B) nutrient utilization, microbial safety and immunity, effect of diets supplemented with lemon, onion and garlic juice fed to growing buffalo calves. World Journal of Agricultural Sciences, 5, 456465.

Arhab, R., Karima, K., Nassima, L., Hakim, B., Besma, H. \& Hacene, B. (2013). Effect of essential oils extracted from Satureja calamintha, Mentha pulegium and Juniperus phoenicea on in vitro methanogenesis and fermentation traits of vetch-oat hay. African Journal of Environmental Science and Technology, 7, 140-144.

Benchaar, C., Calsamiglia, S., Chaves, A. V., Fraser, G. R., Colombatto, D., McAllister, T. A. \& Beauchemin, K. A. (2008a). A review of plant-derived essential oils in ruminant nutrition and production. Animal Feed Science and Technology, 145, 209-228.

Benchaar, C., Chaves, A. V., Fraser, G. R., Wang, Y., Beauchemin, K. A. \& McAllister, T. A. (2007). Effects of essential oils and their components on in vitro rumen microbial fermentation. Canadian Journal of Animal Science, 87, 413-419.

Benchaar, C. \& Greathead, H. (2011). Essential oils and opportunities to mitigate enteric methane emissions from ruminants. Animal Feed Science and Technology, 166, 338-355.

Benchaar, C., McAllister, T. A. \& Chouinard, P. Y. (2008b). Digestion, ruminal fermentation, ciliate protozoal populations, and milk production from dairy cows fed cinnamaldehyde, quebracho condensed tannin, or yucca schidigera saponin extracts. Journal of Dairy Science, 91, 4765-4777.

Boadi, D., Benchaar, C., Chiquette, J. \& Massé, D. (2004). Mitigation strategies to reduce enteric methane emissions from dairy cows: Update review. Canadian Journal of Animal Science, 84, 319-335. 
Bodas, R., Prieto, N., García-González, R., Andrés, S., Giráldez, F. J. \& López, S. (2012). Manipulation of rumen fermentation and methane production with plant secondary metabolites. Animal Feed Science and Technology, 176, 78-93.

Brenes, A. \& Roura, E. (2010). Essential oils in poultry nutrition: Main effects and modes of action. Animal Feed Science and Technology, 158, 1-14.

Bunglavan, S. J. (2014). Methanogenesis and recent techniques for mitigation of methanogenesis in ruminants. Journal of Livestock Science, 5, 35-48.

Busquet, M., Calsamiglia, S., Ferret, A., Cardozo, P. W. \& Kamel, C. (2005a). Effects of cinnamaldehyde and garlic oil on rumen microbial fermentation in a dual flow continuous culture. Journal of Dairy Science, $88,2508-2516$.

Busquet, M., Calsamiglia, S., Ferret, A., Carro, M. D. \& Kamel, C. (2005b). Effect of garlic oil and four of its compounds on rumen microbial fermentation. Journal of Dairy Science, 88, 4393-4404.

Calsamiglia, S., Busquet, M., Cardozo, P. W., Castillejos, L. \& Ferret, A. (2007). Invited review: essential oils as modifiers of rumen microbial fermentation. Journal of Dairy Science, 90, 2580-2595.

Cardozo, P., Calsamiglia, S., Ferret, A. \& Kamel, C. (2006). Effects of alfalfa extract, anise, capsicum, and a mixture of cinnamaldehyde and eugenol on ruminal fermentation and protein degradation in beef heifers fed a highconcentrate diet. Journal of Animal Science, 84, 2801-2808.

Cardozo, P. W., Calsamiglia, S., Ferret, A. \& Kamel, C. (2004). Effects of natural plant extracts on ruminal protein degradation and fermentation profiles in continuous culture. Journal of Animal Science, 82, 3230-3236.

Cardozo, P. W., Calsamiglia, S., Ferret, A. \& Kamel, C. (2005). Screening for the effects of natural plant extracts at different $\mathrm{pH}$ on in vitro rumen microbial fermentation of a high- concentrate diet for beef cattle. Journal of Animal Science, 83, 2572-2579.

Casewell, M., Friis, C., Marco, E., McMullin, P. \& Phillips, I. (2003). The European ban on growth-promoting antibiotics and emerging consequences for human and animal health. Journal of Antimicrobial Chemotherapy, 52, 159-161.

Chaudhry, A. S. \& Khan, M. M. H. (2012). Impacts of different spices on in vitro rumen dry matter disappearance, fermentation and methane of wheat or ryegrass hay based substrates. Livestock Science, 146, 84-90.

Chaves, A. V., Baah, J., Wang, Y., McAllister, T. A. \& Benchaar, C. (2012). Effects of cinnamon leaf, oregano and sweet orange essential oils on fermentation and aerobic stability of barley silage. Journal of the Science of Food and Agriculture, 92, 906-915.

Chaves, A. V., Dugan, M. E. R., Stanford, K., Gibson, L. L., Bystrom, J. M., McAllister, T. A., Van Herk, F. \& Benchaar, C. (2011). A dose-response of cinnamaldehyde supplementation on intake, ruminal fermentation, blood metabolites, growth performance, and carcass characteristics of growing lambs. Livestock Science, 141, 213220.

Chaves, A. V., He, M. L., Yang, W. Z., Hristov, A. N., McAllister, T. A. \& Benchaar, C. (2008a). Effects of essential oils on proteolytic, deaminative and methanogenic activities of mixed ruminal bacteria. Canadian Journal of Animal Science, 88, 117-122.

Chaves, A. V., Schei, I., Wang, Y., McAllister, T. A. \& Benchaar, C. (2009). Effects of carvacrol and cinnamaldehyde on microbial fermentation when added to a barley-or corn-based diet in a continuous-culture system. Canadian Journal of Animal Science, 89, 97-104.

Chaves, A. V., Stanford, K., Dugan, M. E. R., Gibson, L. L., McAllister, T. A., Van Herk, F. \& Benchaar, C. (2008b). Effects of cinnamaldehyde, garlic and juniper berry essential oils on rumen fermentation, blood metabolites, growth performance, and carcass characteristics of growing lambs. Livestock Science, 117, 215-224. 
Chaves, A. V., Stanford, K., Gibson, L. L., McAllister, T. A. \& Benchaar, C. (2008c). Effects of carvacrol and cinnamaldehyde on intake, rumen fermentation, growth performance, and carcass characteristics of growing lambs. Animal Feed Science and Technology, 145, 396-408.

Cieslak, A., Szumacher-Strabel, M., Stochmal, A. \& Oleszek, W. (2013). Plant components with specific activities against rumen methanogens. animal, 7, 253-265.

Craig, W. J. (1999). Health-promoting properties of common herbs. The American Journal of Clinical Nutrition, 70, 491-499.

Cruz, O. T. B., Valero, M. V., Zawadzki, F., Rivaroli, D. C., Prado, R. M., Lima, B. S. \& Prado, I. N. (2014). Effect of glycerine and essential oils (Anacardium occidentale and Ricinus communis) on animal performance, feed efficiency and carcass characteristics of crossbred bulls finished in a feedlot system. Italian Journal of Animal Science, 13, 790-797.

Davidson, P. M. \& Naidu, A. S. (2000). Phytophenols. In: Naidu, A. S. (ed.) Natural Food Antimicrobial Systems. CRC - Press, Boca Raton, FL.

Donald, J. E. \& Ward, G. M. (1996). Estimates of animal methane emissions. Environmental Monitoring and Assessment, 42, 133-141.

Dong, G., Wang, X., Liu, Z. \& Wang, F. (2010). Effects of phytogenic products on in vitro rumen fermentation and methane emission in goats. Journal of Animal and Feed Sciences, 19, 218-219.

Esparza-Borges, H. \& Ortiz-Márquez, A. (1995). Therapeutic efficacy of plant extracts in the treatment of bovine endometritis. International Symposium on Medicinal and Aromatic Plants 426.

Fasseas, M. K., Mountzouris, K. C., Tarantilis, P. A., Polissiou, M. \& Zervas, G. (2008). Antioxidant activity in meat treated with oregano and sage essential oils. Food Chemistry, 106, 1188-1194.

FDA. (2004). Food and Drug Administration of the US, Substances used as GRAS in food. 21, CFR 184.
Frankic, T., Voljč, M., Salobir, J. \& Rezar, V. (2009). Use of herbs and spices and their extracts in animal nutrition. Acta Agriculturae Slovenica, 94, 95-102.

Fraser, G. R., Chaves, A. V., Wang, Y., McAllister, T. A., Beauchemin, K. A. \& Benchaar, C. (2007). Assessment of the effects of cinnamon leaf oil on rumen microbial fermentation using two continuous culture systems. Journal of Dairy Science, 90, 2315-2328.

Gebrehiwot, T. (2014). Rumen manipulation for enhanced feed utilization and improved productivity performance of ruminants: A review. Momona Ethiopian Journal of Science, 6, 3-17.

Geraci, J. I., Garciarena, A. D., Gagliostro, G. A., Beauchemin, K. A. \& Colombatto, D. (2012). Plant extracts containing cinnamaldehyde, eugenol and capsicum oleoresin added to feedlot cattle diets: Ruminal environment, short term intake pattern and animal performance. Animal Feed Science and Technology, 176, 123-130.

Gladine, C., Morand, C., Rock, E., Gruffat, D., Bauchart, D. \& Durand, D. (2007a). The antioxidative effect of plant extracts rich in polyphenols differs between liver and muscle tissues in rats fed $n-3$ PUFA rich diets. Animal Feed Science and Technology, 139, 257-272.

Gladine, C., Rock, E., Morand, C., Bauchart, D. \& Durand, D. (2007b). Bioavailability and antioxidant capacity of plant extracts rich in polyphenols, given as a single acute dose, in sheep made highly susceptible to lipoperoxidation. British Journal of Nutrition, 98, 691-701.

Goodrich, R. D., Garrett, J. E., Gast, D. R., Kirick, M. A., Larson, D. A. \& Meiske, J. C. (1984). Influence of monensin on the performance of cattle. Journal of Animal Science, 58, 14841498.

Greathead, H. (2003). Plants and plant extracts for improving animal productivity. Proceedings of the Nutrition Society, 62, 279-290.

Groussin, A.-L. \& Antoniotti, S. (2012). Valuable chemicals by the enzymatic modification of molecules of natural origin: Terpenoids, 
steroids, phenolics and related compounds. Bioresource Technology, 115, 237-243.

Gunjan, G. \& Makkar, H. P. S. (2012). Methane mitigation from ruminants using tannins and saponins. Tropical Animal Health and Production, 44, 729-739.

Hassanat, F. \& Benchaar, C. (2012). Assessment of the effect of condensed (acacia and quebracho) and hydrolysable (chestnut and valonea) tannins on rumen fermentation and methane production in vitro. Journal of the Science of Food and Agriculture.

Ipharraguerre, I. R. \& Clark, J. H. (2003). Usefulness of ionophores for lactating dairy cows: a review. Animal Feed Science and Technology, 106, 39-57.

Janz, J., Morel, P., Wilkinson, B. \& Purchas, R. (2007). Preliminary investigation of the effects of low-level dietary inclusion of fragrant essential oils and oleoresins on pig performance and pork quality. Meat Science, 75, 350-355.

Jayasena, D. D. \& Jo, C. (2013). Essential oils as potential antimicrobial agents in meat and meat products: A review. Trends in Food Science \& Technology, 34, 96-108.

Kim, E., Kim, C.-H., Min, K.-S. \& Lee, S. (2012a). Effects of plant extracts on microbial population, methane emission and ruminal fermentation characteristics in in vitro. AsianAustralasian Journal of Animal Sciences, 25, 806-811.

Kim, S. C., Adesogan, A. T. \& Shin, J. H. (2012b). Effects of dietary addition of wormwood (Artemisia montana Pampan) silage on growth performance, carcass characteristics, and muscle fatty acid profiles of beef cattle. Animal Feed Science and Technology, 177, 15-22.

Kraszewski, J., Wawrzynczak, S. \& Wawrzynski, M. (2002). Effect of herb feeding on cow performance, milk nutritive value and technological suitability of milk for processing. Roczniki Naukowe Zootechniki, 2, 147-158.

Kudke, R., Kalaskar, S. \& Nimbalkar, R. (1999). Neem leaves as feed supplement for livestock. Pushudhn, 14, 12-14.
Lippens, M., Huyghebaert, G. \& Cerchiari, E. (2005). Effect of the use of coated plant extracts and organic acids as alternatives for antimicrobial growth promoters on the performance of broiler chickens. Archiv Fur Geflugelkunde, 69, 261.

Marcus, J. B. (2013). Chapter 3 - Culinary Arts Basics: Healthy Cooking Fundamentals: The Culinary Competencies of Healthy Food Selection, Preparation and Food Service. In: Marcus, J. B. (ed.) Culinary Nutrition. Academic Press, San Diego.

Mariam, A. G., El-Zarkouny, S. Z., El-Shazly, K. A. \& Sallam, S. M. A. (2014). Impact of essential oils blend on methane emission, rumen fermentation characteristics and nutrient digestibility in barki sheep. Journal of Agricultural Science, 6, 144.

Mohammad, E. N. S. \& Moeini, M. M. (2015). The influence of ginger (Zingiber Officinale) on in vitro rumen fermentation patterns. Annual Research \& Review in Biology, 5, 54-63.

Moreira, F. B. \& Prado, I. N. (2010). Sazonalidade na produção e qualidade de plantas forrageiras. In: Prado, I. N. (ed.) Produção de bovinos de corte e qualidade da carne. Eduem, Maringá, Paraná, Brasil.

Odoemelam, V. U., Etuk, I. F., Ndelekwute, E. K. \& Ekwe, T. C. I. C. C. (2013). Herbs and spices: Options for sustainable animal production. Journal of Biology, Agriculture and Healthcare, 3, 116-123.

OJEU. (2003). Regulation (EC) No 1831/2003 of the European Parliament and the Council of 22 September 2003 on additives for use in animal nutrition. Official Journal of European Union. Brussels, Belgium.

Pasqua, R., Hoskins, N., Betts, G. \& Mauriello, G. (2006). Changes in membrane fatty acids composition of microbial cells induced by addiction of thymol, carvacrol, limonene, cinnamaldehyde, and eugenol in the growing media. Journal of Agricultural and Food Chemistry, 54, 2745-2749.

Patra, A. K. 2011. Effects of essential oils on rumen fermentation, microbial ecology and 
ruminant production. Asian Journal of Animal Veterinary Advances, 6, 416-428.

Patra, A. K. (2012). Enteric methane mitigation technologies for ruminant livestock: a synthesis of current research and future directions. Environmental Monitoring and Assessment, 184, 1929-1952.

Patra, A. K. \& Saxena, J. (2010). A new perspective on the use of plant secondary metabolites to inhibit methanogenesis in the rumen. Phytochemistry, 71, 1198-1222.

Patra, A. K. \& Saxena, J. (2011). Exploitation of dietary tannins to improve rumen metabolism and ruminant nutrition. Journal of the Science of Food and Agriculture, 91, 24-37.

Rezaei, N. \& Pour, H. A. (2012). Evaluation effect of thyme extract on degradability of soybean meal with gas product technique. Advances in Bioresearch, 3, 45-47.

Russell, J. B. \& Houlihan, A. J. (2003). Ionophore resistance of ruminal bacteria and its potential impact on human health. FEMS Microbiology Reviews, 27, 65-74.

Srinivasan, K. (2005). Spices as influencers of body metabolism: an overview of three decades of research. Food Research International, 38, 77-86.

Szumacher-Strabel, M. \& Cieślak, A. (2010). Potential of phytofactors to mitigate rumen ammonia and methane production. Journal of Animal and Feed Sciences, 19, 319-337.

Tag El-Din, A. E., Moharam, M. S., Nour, A. A. \& Nasser, M. E. (2012). Effect of some herbs on the rumen fermentation: 1- Effect of ginger (zingiber officinale) and garlic (allium sativum) on gas production, energy values, organic matter digestibility and methane emission, in vitro. Journal of Agricultural and Environnementa Science, 11, 33-53.

Tamminga, S. (1992). Nutrition management of dairy cows as a contribution to pollution control. Journal of Dairy Science, 75, 345-357.

Teferedegne, B. (2000). New perspectives on the use of tropical plants to improve ruminant nutrition. Proceedings of the Nutrition Society, 59, 209-214.
Vadivel, V., Nandety, A. \& Biesalski, H. K. (2011). Antioxidant potential and health relevant functionality of traditionally processed Cassia hirsuta L. seeds: An Indian underutilized food legume. Plant Foods for Human Nutrition, $66,245-253$.

Valero, M. V., Prado, R. M., Zawadzki, F., Eiras, C. E., Madrona, G. S. \& Prado, I. N. (2014a). Propolis and essential oils additives in the diets improved animal performance and feed efficiency of bulls finished in feedlot. Acta Scientiarum. Animal Sciences, 36, 419-426.

Valero, M. V., Torrecilhas, J. A., Zawadzki, F., Bonafé, E. G., Madrona, G. S., Prado, R. M., Passetti, R. A. C., Rivaroli, D. C., Visentainer, J. V. \& Prado, I. N. (2014b). Propolis or cashew and castor oils effects on composition of Longissimus muscle of crossbred bulls finished in feedlot. Chilean Journal of Agricultural and Research, 74, 445-451.

Valero, M. V., Zawadzki, F., Prado, R. M., Fugita, C. A., Rivaroli, D. C., Ornaghi, M. \& Prado, I. N. (2015). Propolis and functional oils (cashew and castor oils) on animal performance, apparent digestibility and blood cells of growing crossbred bulls reared in an intensive system. Revista Colombiana de Ciencias Pecuarias, in press.

Van Soest, P. J. (1994). Nutritional ecology of the ruminant. Cornell University Press, Ithaca, NY, USA.

Waghorn, G., Jones, W., Shelton, I. \& McNabb, W. (1990). Condensed tannins and the nutritive value of herbage. Proceedings of the New Zealand Grassland Association.

Wanapat, M. 2000. Rumen manipulation to increase the efficient use of local feed resources and productivity of ruminants in the tropics. Asian-Australasian Jounral of Animal Sciences, 13, 59-67.

Wanapat, M., Polyorach, S., Boonnop, K., Mapato, C. \& Cherdthong, A. (2009). Effects of treating rice straw with urea or urea and calcium hydroxide upon intake, digestibility, rumen fermentation and milk yield of dairy cows. Livestock Science, 125, 238-243. 
Windisch, W., Schedle, K., Plitzner, C. \& Kroismayr, A. (2008). Use of phytogenic products as feed additives for swine and poultry. Journal of Animal Science, 86, E140E148.

Zawadzki, F., Prado, I. N., Marques, J. A., Zeoula, L. M., Prado, R. M., Fugita, C. A., Valero, M. V. \& Maggioni, D. (2011). Sodium monensin or propolis extract in the diet of Nellore bulls finished in feedlot: chemical composition and fatty acid profile of Longissimus muscle. Semina: Ciências Agrárias, 32, 1627-1636.

Zigger, D. (2001). Healthier pigs on diet with garlic and cinnamon. Feed Technology, 5, 9-17.
Received in January 21, 2016

Accepted in March 5, 2016

License information: This is an open-access article distributed under the terms of the Creative Commons Attribution License, which permits unrestricted use, distribution, and reproduction in any medium, provided the original work is properly cited 